\title{
Strategies Developed by Toxoplasma gondii to Survive in the Host
}

\author{
Wanbo Zhu ${ }^{1,2 \dagger}$, Jingyang $\mathrm{Li}^{1,3 \dagger}$, Faustina Pappoe ${ }^{4}$, Jilong Shen ${ }^{1 *}$ and $\mathrm{Li} \mathrm{Yu}^{1 *}$ \\ 'Department of Microbiology and Parasitology, Anhui Provincial Laboratory of Microbiology and Parasitology, Anhui Key \\ Laboratory of Zoonoses, Anhui Medical University, Hefei, China, '2Graduate School of Affiliated Anhui Provincial Hospital, \\ Anhui Medical University, Hefei, China, ${ }^{3}$ The Clinical Laboratory of the Third People's Hospital of Heifei, Hefei, China, \\ ${ }^{4}$ Department of Microbiology and Immunology, School of Medical Sciences, University of Cape Coast, Cape Coast, Ghana
}

OPEN ACCESS

Edited by:

Rustam Aminov

University of Aberdeen,

United Kingdom

Reviewed by:

Bang Shen,

Huazhong Agricultural University,

China

Sébastien Besteiro,

Université de Montpellier, France

*Correspondence:

Jilong Shen

shenjilong53@126.com

$\mathrm{LiYu}$

lilyyu33@126.com

tThese authors have contributed equally to this work

Specialty section:

This article was submitted to Infectious Diseases,

a section of the journal

Frontiers in Microbiology

Received: 04 January 2019

Accepted: 09 April 2019

Published: 26 April 2019

Citation:

Zhu W, Li J, Pappoe F, Shen J and Yu L (2019) Strategies Developed by Toxoplasma gondii to Survive

in the Host.

Front. Microbiol. 10:899.

doi: 10.3389/fmicb.2019.00899
One of the most successful intracellular parasites, Toxoplasma gondii has developed several strategies to avoid destruction by the host. These include approaches such as rapid and efficient cell invasion to avoid phagocytic engulfment, negative regulation of the canonical CD40-CD40L-mediated autophagy pathway, impairment of the noncanonical IFN- $\boldsymbol{\gamma}$-dependent autophagy pathway, and modulation of host cell survival and death to obtain lifelong parasite survival. Different virulent strains have even evolved different ways to cope with and evade destruction by the host. This review aims to illustrate every aspect of the game between the host and Toxoplasma during the process of infection. A better understanding of all aspects of the battle between Toxoplasma and its hosts will be useful for the development of better strategies and drugs to control the parasite.

Keywords: Toxoplasma, intracellular parasites, cell invasion, immune evasion, autophagy

\section{TOXOPLASMA AND HOST IMMUNITY}

Toxoplasma gondii is an obligate intracellular protozoan parasite with a unique apical complex composed of specialized cytoskeletal and secretory organelles, including micronemes, rhoptries, and dense granules. T. gondii is the single species in the genus Toxoplasma, although recent studies revealed that it has many genetic types distributed across the continents. In North America and Europe, populations of T. gondii are dominated by three archetypal types (I, II, or III) (Darde et al., 1992; Howe and Sibley, 1995; Howe et al., 1997; Ajzenberg et al., 2002), which vary substantially in virulence. Type I strains are highly virulent to mice with an LD100 as low as a single parasite, whereas strains of types II and III are less virulent (LD100 > 1,000) (Sibley and Boothroyd, 1992; Sibley et al., 2009). Unlike in North America and Europe, strains of T. gondii in South America are much more genetically diverse. Chinese 1, however, has been reported to be the most common type in East Asia, especially in China (Zhou et al., 2010, 2011; Chen et al., 2011; Wang et al., 2013; Li et al., 2014).

T. gondii is one of the most successful parasites, capable of invading and replicating within almost all nucleated cells of warm-blooded animals including humans (Dubey, 2010). The distinctive characteristic of this parasite is its ability to induce long-term chronic infections through its interactions with the host, leading to conversion of the prolific tachyzoite stage to the quiescent bradyzoite parasite stage (Aliberti, 2005). Bradyzoite forms of the parasite are not usually harmful in immunocompetent individuals, although in immunodeficient individuals, such as tumor and AIDS patients, they reconvert into cytolytic tachyzoites, resulting in severe toxoplasmosis and distant dissemination (Ayoade et al., 2017). Despite the parasite being the subject of over 100 years of studies and efficient therapies against acute toxoplasmosis have 
been developed, no effective approach for chronic infection of bradyzoites has been found because of its survival strategies in the host.

Among different hosts of $T$. gondii, there are natural differences in susceptibility to the parasite, and host innate immunity is known to play a critical role in susceptibility to the infection. Most laboratory mouse strains are susceptible to infection, and therefore they have been widely used for studying immune responses against $T$. gondii. In mice, parasite profilin interacts with Toll-like receptor (TLR)11 and TLR12 on dendritic cells (DCs) to generate a potent interleukin-12 (IL-12) response in a myeloid differentiation factor 88 (MyD88)-dependent manner (Yarovinsky et al., 2005; Koblansky et al., 2013). Distinct from these stimuli, binding of the T. gondii protein cyclophilin-18 (C-18) to the chemokine receptor CCR5 can also activate murine DCs to produce IL-12 (Aliberti et al., 2003). As a pro-inflammatory cytokine, IL-12 stimulates $\mathrm{NK}$ cells, $\mathrm{CD} 4^{+} \mathrm{T}$ cells, and $\mathrm{CD} 8^{+}$ $\mathrm{T}$ cells to express interferon- $\gamma$ (IFN- $\gamma)$, which plays a crucial role in parasite survival during infection. IFN- $\gamma$ is also produced by neutrophils in response to IL- $1 \beta$ and TNF. IFN- $\gamma$ propagates a signal to activate the signal transducer and activator of transcription 1 (STAT1) (see Glossary) through the surface receptor, IFN $-\gamma$ R. STAT1 is critical for the host immune response against T. gondii infection. STAT1 upregulates the production of effector molecules such as nitric oxide (NO) and reactive oxygen species (ROS), both of which are responsible for controlling parasite invasion in mice. IFN- $\gamma$ also triggers the induction of immunity-related GTPase (IRG) proteins and guanylate-binding proteins (GBPs) to damage the parasitophorous vacuole membrane (PVM) in mice. Additionally, an IFN- $\gamma$-independent mechanism in mouse naive macrophages was found recently, in which NADPH oxidase (Nox)-generated ROS and GBP5 restrict the replication of avirulent type III parasites (Matta et al., 2018).

Unlike mice, humans are quite resistant to $T$. gondii infection. Owing to lack of functional genes encoding the key innate sensors TLR11 and TLR12 (Roach et al., 2005), human cells have different innate immune sensing mechanisms for the parasite. A recent research revealed that the human recognition system for this parasite is based on detection of the damage-associated molecule S100A11 released from infected cells and RAGEdependent induction of CCL2 (Safronova et al., 2019). Human cells also rely on IFN- $\gamma$ and STAT1 signaling to control the replication of T. gondii in vitro (Ceravolo et al., 1999), although different mechanisms are explored to control intracellular parasites. Firstly, indoleamine oxidase (IDO), but not inducible nitric oxide synthase (iNOS), has been found to be an important effector to control the parasite replication in several human cell lines after IFN- $\gamma$ stimulation (Pfefferkorn et al., 1986; Nagineni et al., 1996); secondly, human cells are absent in IFN-inducible fulllength IRG genes and proteins (Bekpen et al., 2005; Howard et al., 2011). Although human cells express a wide repertoire of GBPs, the involvement of GBPs in the human anti-T. gondii response in different cell lines is controversial (Ohshima et al., 2014; Johnston et al., 2016). Therefore, it appears that two of the main mechanisms of innate resistance mediated by IRGs and GBPs in IFN- $\gamma$ stimulated mouse cells are not highly active in human cells (Hakimi et al., 2017).
Rats, like humans, are quite resistant to Toxoplasma infection but vary in their susceptibilities depending on the rat strain (Dubey et al., 2016). The Lewis (LEW) strain exhibits a complete resistance to Toxoplasma infection, and its resistance is partially abrogated by neutralization of endogenous IFN- $\gamma$, which showed that IFN- $\gamma$ plays some role in the resistance of rats (Sergent et al., 2005). The Toxo1 locus containing Nlrp1 (nucleotide-binding oligomerization domain, leucine-rich repeat protein 1) was identified to mediate resistance to T. gondii infection (Cavailles et al., 2006). T. gondii can activate the NLRP1 inflammasome in macrophages, leading to caspase1 -induced pyroptosis and release of the pro-inflammatory cytokines IL-1 $\beta$ and IL-18 (Cavailles et al., 2014; Cirelli et al., 2014). GRA35, GRA42, and GRA43 have been recently found to be required for induction of macrophage pyroptosis in Lewis rats (Wang et al., 2019).

\section{EFFICIENT INVASION IS REQUIRED FOR PARASITE SURVIVAL}

Because T. gondii is an obligate intracellular parasite, a successful and efficient cell invasion is crucial for its survival. To establish a successful invasion, T. gondii needs a coordinated sequential secretion of microneme and rhoptry neck proteins (RON) first to mediate the invasion. A secretion set of T. gondii, including ROPs and GRAs, is also involved in host modulation and longterm establishment of the parasite into the host cell. The unique invasion mechanism of T. gondii consists of a secretion-regulated moving junction (MJ), which facilitates firm attachment between the parasite and the host plasma membranes (Alexander et al., 2005; Lebrun et al., 2005; Lamarque et al., 2011), and the glideosome, which is a specific motor system of the parasite. Formation of the MJ relies on apical membrane antigen 1 (AMA1), secreted from micronemes and translocated to the parasite's plasma membrane, and a rhoptry neck complex (composed of RON2, RON4, RON5, and RON8 proteins), secreted from rhoptry necks and exported into the host cell (Besteiro et al., 2009; Lamarque et al., 2011; Tyler and Boothroyd, 2011; Guerin et al., 2017). RON2 exposes a short segment at the surface of the host cell that serves as a ligand for AMA1, thus forming an intimate contact to generate an irreversible interaction between the host cell and the parasite (Lamarque et al., 2011; Tonkin et al., 2011; Tyler and Boothroyd, 2011). In addition to AMA1 and RON2, T. gondii has three additional AMA paralogs and two additional RON2 paralogs, which form three complexes: AMA2-RON2, AMA3-RON2L2, and AMA4-RON2L1 (Poukchanski et al., 2013; Lamarque et al., 2014; Parker et al., 2016). The exceptional molecular diversity at the parasite-host cell interface may explain why the parasite has such a wide host range. Microneme proteins like MIC4-1-6, MIC2-M2AP, and MIC3-8 complex also play a key role in adhesion that supports gliding motility and host cell invasion (Rabenau et al., 2001; Soldati et al., 2001; Meissner et al., 2002a; Wang and Yin, 2015; Gras et al., 2017). The glideosome is an actin-myosin motor complex in T. gondii, and it is composed of a short single-headed myosin heavy chain A (MyoA), a myosin light 
chain (TgMLC1), and three gliding-associated proteins, TgGAP45, TgGAP50, and TgGAP40 (Herm-Gotz et al., 2002; Meissner et al., 2002b; Frenal et al., 2010). The connection between the glideosome and the MJ complex was previously thought to be mediated by aldolase (Jewett and Sibley, 2003; Boucher and Bosch, 2015); however, it was recently identified to be mediated by glideosome-associated connector (GAC), which forms a bridge between cell surface adhesins and the actin cytoskeleton in the parasite (Jacot et al., 2016). Finally, the power produced by the motor complex enables the parasite to move to potential host cells and to enter them by pushing forward the host membrane.

After active invasion of the host cell, Toxoplasma dissociates from the host membrane and resides within a non-fusogenic parasitophorous vacuole (PV), which provides a physical niche for the parasite (Tahara et al., 2016). PV formation is a result of invagination of the host cell membrane and involves host cytoskeleton rearrangement, ROPs, and GRAs (Clough and Frickel, 2017). For parasite growth and proliferation, PVM is selectively permeable to small molecules and nutrients from the host through GRA17 and GRA23 (Gold et al., 2015). More importantly, as a physical barrier, the PV protects parasites from fusion with host lysosomes and endosomes, thereby enabling survival of the parasite (Mordue and Sibley, 1997; Pavlou et al., 2018).

\section{CELL AUTOPHAGY IN HOST IMMUNITY AND TOXOPLASMA EVASION}

Classical autophagy, a highly evolutionarily conserved catabolic process, is a multistep lysosomal process in which intracellular damaged or superfluous proteins and organelles are engulfed by a double-membraned autophagosome and degraded after fusion with a lysosome (Deter et al., 1967; Mizushima et al., 2011; Ohsumi, 2014). Autophagy is also actively involved in the capture of intracellular parasites and routing them for destruction. This selective autophagy process is called xenophagy, a key defense mechanism against a broad range of infections (Deretic et al., 2013; Besteiro, 2018). In addition to classic autophagy, some noncanonical forms of autophagy are also involved in host defense against intracellular pathogens: LC3-associated phagocytosis (LAP) and IFN $\gamma$ - inducible GTPasemediated host defense. These processes rely on some but not all components of the autophagy machinery (Zhao et al., 2008; Lai and Devenish, 2012; Haldar et al., 2014).

In $T$. gondii-infected human/murine macrophages and nonhematopoietic cells, CD40 interacts with CD40L (CD154) expressed on the surface of $\mathrm{T}$ cells to trigger the killing of the parasite through an autophagy-dependent pathway (Andrade et al., 2006; Portillo et al., 2010; Van Grol et al., 2013). $\mathrm{CD} 40-\mathrm{CD} 40 \mathrm{~L}$ interactions activate upstream regulators of the autophagic response such as ULK1/2 and Beclin1-PI3KC3, two important complexes required for the initiation of phagophore (an isolation membrane, precursor of the autophagosomal compartment), and then drive the recruitment of the protein LC3 to the phagophore and promote autophagosome formation (Liu et al., 2016). In contrast, IFN $\gamma$-dependent noncanonical autophagy directly binds LC3 and other Atgs to the PVM, leading to recruitment of two subclasses of IFN $\gamma$-inducible GTPases for parasite exposure (Selleck et al., 2015). Atgs in both canonical and noncanonical autophagy processes mediate the targeting of parasites and

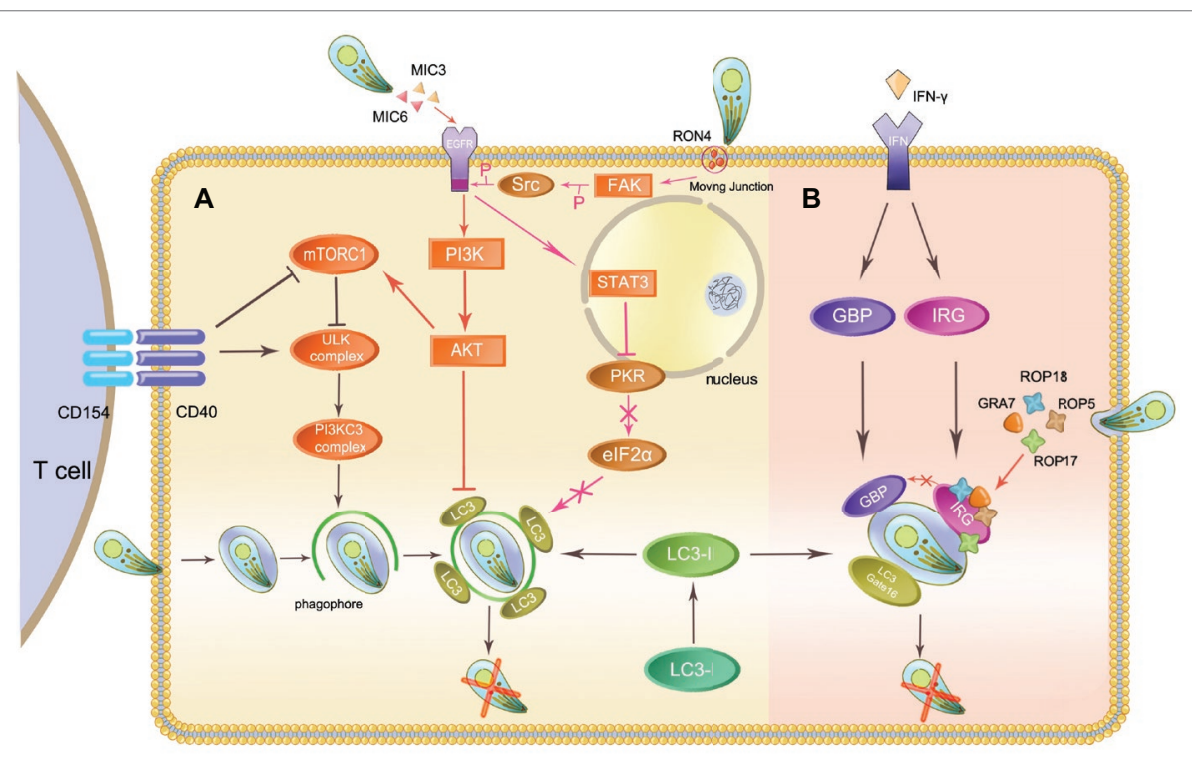

FIGURE 1 | Autophagy initiates host immunity and Toxoplasma immune evasion. The host eliminates intracellular Toxoplasma through autophagy proteins in two ways: the canonical CD40-CD40L-mediated and the noncanonical IFN- $\gamma$-dependent autophagy pathways. Toxoplasma can evade elimination through host autophagy by following means. (A) In the canonical autophagy pathway, MIC3, and MIC6 secreted from Toxoplasma phosphorylate EGFR and activate the PI3K/AKT signaling pathway, which has an impact on LC3 function. The activation of FAK-Src through Toxoplasma invasion prevents this parasite from being targeted. (B) ROP5, ROP18, and GRA7 form a complex with ROP17 and load onto the PVM, inactivating IRGs through phosphorylation. 
expose Toxoplasma to host immune surveillance, leading to killing of the parasite. To avoid being targeted, Toxoplasma developed a survival strategy against autophagy that involves immune evasion (Figure 1A).

The Toxoplasma micronemal proteins MIC3, and MIC6 act as ligands for EGFR, inducing phosphorylation of this protein in host cells and activating the PI3K/Akt signaling pathway. This event prevents the expression of the autophagy protein LC3 and vacuole-lysosomal fusion. Subsequently, the parasite is prevented from being targeted by the host autophagy machinery (Muniz-Feliciano et al., 2013; Wang et al., 2016). In mammalian cells, Akt phosphorylation also results in the activation of mTORC1, which negatively regulates autophagosome formation, thus inhibiting autophagy (Kim et al., 2011). During host invasion and MJ formation, T. gondii activates a signaling cascade downstream of FAK-Src. It inhibits the activation of the key stimulators of autophagy PKR and eIF2 $\alpha$, which prevent the parasite from being targeted (Portillo et al., 2017).

\section{ESCAPE FROM GTPases-DEPENDENT ANTIMICROBIAL PROGRAMS}

As mentioned above, the IFN $\gamma$-inducible GTPase-mediated host defense plays a crucial role in the destruction of the PVM in a murine model. In IFN $\gamma$-stimulated cells, a complex containing LC3 and a subset of Atgs attaches to the PVM and recruits IFN $\gamma$-inducible GTPases, leading to vesiculation and destruction of the PVM (Lai and Devenish, 2012). Consequently, the parasites are released into the host cell cytoplasm and subsequently become exposed to the host immune system. Recent reports indicate that Gate-16 is also required for this GTPases-dependent antimicrobial program even in the absence of LC3 (Sasai et al., 2017).

Virulent type I strains of T. gondii can evade this autonomous host immunity mechanism but type II and III strains cannot. Rhoptry protein kinase ROP18 and pseudokinase ROP5 are known to be polymorphic and determine the virulence of different strains and thwart the IRG system (Niedelman et al., 2012). After being secreted during invasion, ROP18 phosphorylates Thr residues in the switch region 1 (SW1) on host Irga6 and Irgb6 with the cooperation of ROP5. ROP5 regulates the activity of ROP18, and additionally binds directly to monomeric IRGs to prevent oligomerization and support ROP18 phosphorylation. ROP5 is also able to associate with another PVM-associated kinase, ROP17, in phosphorylating and inactivating IRGs (Irgb6) (Etheridge et al., 2014). GRA7 binds to and increases turnover of Irga6, which makes substrates available for ROP18, thereby preventing loading of IRGs (Figure 1B; Alaganan et al., 2014; Hermanns et al., 2016). ROP5 and ROP18 are also able to inhibit GBP1 loading onto the PVM. Pseudokinase ROP54 can move to the cytoplasmic face of the PVM and restrict immune loading of GBP2 to evade the GBP2-mediated immune response (Yang et al., 2017a). In addition, ROP18 in virulent strains can phosphorylate activating transcription factor $6 \beta$ (ATF6 $\beta$ ), an important factor for DCs antigen presenting
(Yamamoto et al., 2011; Yamamoto and Takeda, 2012). Phosphorylated ATF6 $\beta$ may be degraded and affect the antigenpresenting ability of DCs, having an impact on the interferoninducible GTPase-mediated host defense.

\section{RESISTANCE TO OXIDATIVE STRESS}

Escape from GTPase-dependent antimicrobial programs is vital to $T$. gondii, and innate immune cells cytotoxicity is essential for restriction of parasite infection (Figure 2). Resistance to cytotoxicity makes sense for T. gondii. Inducible nitric oxide synthase (iNOS) expressed by mouse macrophages synthesizes NO through oxidation of L-arginine. Large amounts of NO result in parasite death but can be easily inhibited by $T$. gondii for sustained replication. The process is mediated by TGF $\beta 1$ induction through Smad2 and Smad3, leading to destruction of iNOS and actin filament (F-actin) depolymerization. After infection, high levels of arginase compete with iNOS for the same substrate, leading to a reduction of NO (Padrao Jda et al., 2014). T. gondii HSP70 (TgHSP70), a tachyzoite-specific protein, also contributes to downregulation of NO (Moroda et al., 2017). In human cells, the effect of iNOS is different. It acts as a pro-Toxoplasma host factor through the GRA15-dependent virulence mechanism in the THP-1/Huh7 coculture mode (Bando et al., 2018). Upregulation of ROS and IDO generated by many cell types leads to inhibition of parasite replication. An oxidative stress microenvironment is generated by producing hydrogen peroxide, superoxide, and hydroxyl radicals to damage the parasites or reduce tryptophan levels, preventing the parasites from rapid replication. However, T. gondii can subvert these mechanisms through an antioxidant network. The cytosolic peroxiredoxins TgPRX1 and TgPRX2 and mitochondrial peroxiredoxin TgPRX3 act downstream of superoxide dismutases (SODs) to detoxify hydrogen peroxide (Kwok et al., 2003). TgSOD2 and TgSOD3, similar to mitochondrial SODs, are able to eliminate the ROS produced by oxidative phosphorylation. T. gondii antioxidant glutathione-S-transferase (TgGST), glutaredoxin (TgGrx), and catalase also make a major contribution to decomposing superoxide anion radicals and resisting oxidative damage (Pino et al., 2007; Wang et al., 2015). T. gondii thioredoxin reductase (TgTR) maintains a thioredoxin-reduced state during NADPH consumption that protects parasite against oxidative-burst injury (Kim et al., 2017; Xue et al., 2017). However, this survival ability may only occur in virulent strains, whereas avirulent type III parasites are preferentially cleared by NADPH oxidase and induction of GBP5 in human cells (Matta et al., 2018).

\section{REGULATION OF HOST GENE EXPRESSION BY T. GONDII}

Interferon-inducible cell autonomous immunity or cytotoxicity, necessary for the host to control the parasite, is based on gene expression. These signal transduction pathways enhance 


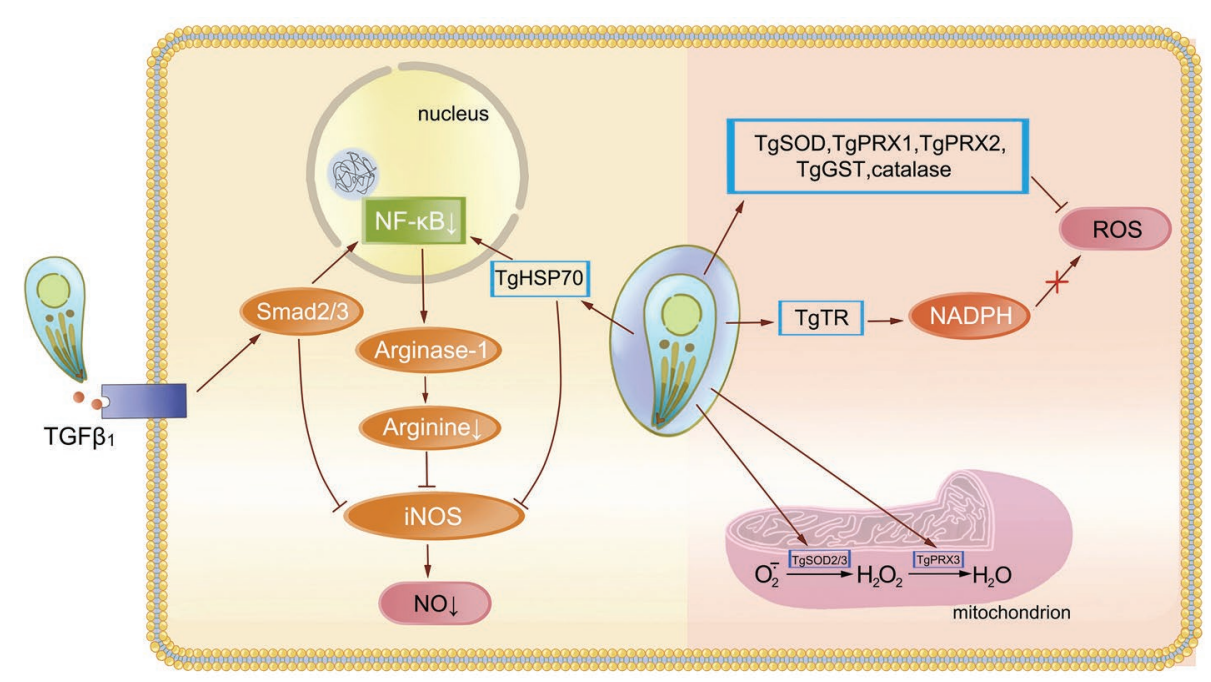

FIGURE 2 | Resistance of Toxoplasma gondii to oxidative stress. Oxidative stress is an important way for the host to restrict Toxoplasma replication and prevent subsequent infection. Activation of TGF $\beta 1$ induced by Toxoplasma through Smad2 and Smad3 leads to destruction of iNOS. The NF-kB pathway is responsible for this decline in NO levels, whereas TgHSP70 also regulates this pathway. Cytosolic peroxiredoxins (TgPRXs) and superoxide dismutases (TgSODs) from Toxoplasma are able to eliminate ROS and protect the parasite against oxidative-burst injury.

or regulate the overall immune response in such a way as to become subverted by T. gondii, constituting a major part of the $T$. gondii immune evasion mechanism (Figure 3).

STAT pathways modulate the transcription of both proand anti-inflammatory molecules for parasite control. The STAT1 transcription factor, the main signal transducer of IFN- $\gamma$, mediates interferon-inducible immunity but may be blocked by the Toxoplasma inhibitor of STAT1-dependent transcription (TgIST), resulting in blockage of interferon regulatory factor 1 (Irf1), p65 GBPs, iNOS, indoleamine 2, 3-dioxygenase 1, and major histocompatibility complex (MHC). Secreted by $T$. gondii after invasion, TgIST translocates to the nucleus and recruits the $\mathrm{Mi}-2$ nucleosome remodeling and deacetylase (NuRD) complex to STAT1-dependent promoters, leading to chromatin alteration and signal blockage (Gay et al., 2016; Olias et al., 2016). In addition, this mechanism is not virulence-dependent, and thus all T. gondii clonal lineages equally inhibit STAT1 transcriptional activity and repress the IFN- $\gamma$ response (Rosowski and Saeij, 2012). Another mechanism of IFN- $\gamma$ blockage through STAT1 is dephosphorylation by suppressor of cytokine signaling phosphatase (SOCS1), an anti-inflammatory pathway that is upregulated during parasite infection.

Transcription factors STAT3 and STAT6 are associated with IL-4 and IL-6 production. After being injected into host cells, ROP16 localizes to the host nucleus through nuclear localization signals. ROP16 can disturb the host IFN- $\gamma$ signal transduction and phosphorylates STAT3 and STAT6, leading to a decrease in IL-12 levels that mainly limits the protective Th1 cytokine responses and the inflammasome. Phosphorylation of STAT6 also induces the expression of arginase-1, SOCS2, and interferon regulatory factor 4 (IRF4). High levels of production of arginase-1 lead to NO degradation, resulting in resistance to host immune attacks, thereby allowing proliferation of the parasite. Although all three strain types initially induce STAT3 and STAT6 activity, only ROP16 I/III strains suppress IL-12 production in macrophages, because a single amino acid substitution in the kinase domain was identified in ROP16 II that determines the strain difference in terms of Stat 3 activation (Yamamoto et al., 2009). ROP16 also induces the phosphorylation and nuclear translocation of STAT5 to generate protective immunity (Chang et al., 2015).

In addition to IRFs, CD40 and TNF, as downstream factors of NF- $\kappa B$ signaling pathway, are also required for parasite control. The NF- $\kappa \mathrm{B}$ family of transcription factors plays a key role in host immunity against $T$. gondii because it is believed to be an evolutionarily conserved mechanism that regulates host innate and adaptive immune functions for parasite survival. ROP18 in T. gondii type I strains is responsible for p65 degradation and thus suppresses NF- $\kappa \mathrm{B}$ activation (Du et al., 2014). NF- $\kappa$ B can also be inhibited by T. gondii excretory/secretory antigens (TgESAs), which limit the functional activity of macrophages and suppress pro-inflammatory cytokine secretion for parasite survival (Wang et al., 2017). In addition, release of GRA15 by type II strains activates the NF- $\kappa \mathrm{B}$ pathway and initiates IL-12 synthesis through enhancing the expression of CD40 in infected cells (Morgado et al., 2014). Thus, type II GRA15 has the ability to effectively control acute $T$. gondii infection and promote the conversion of parasite into bradyzoites at the chronic infection stage. This mechanism is considered another T. gondii immune evasion strategy.

Other T. gondii GRA and ROP effectors contribute to host gene targeting and signaling interference. GRA6 selectively activates nuclear factor of activated T cells 4 (NFAT4), a host transcription factor, which modulates host immune responses and parasite dissemination in a strain-specific manner 


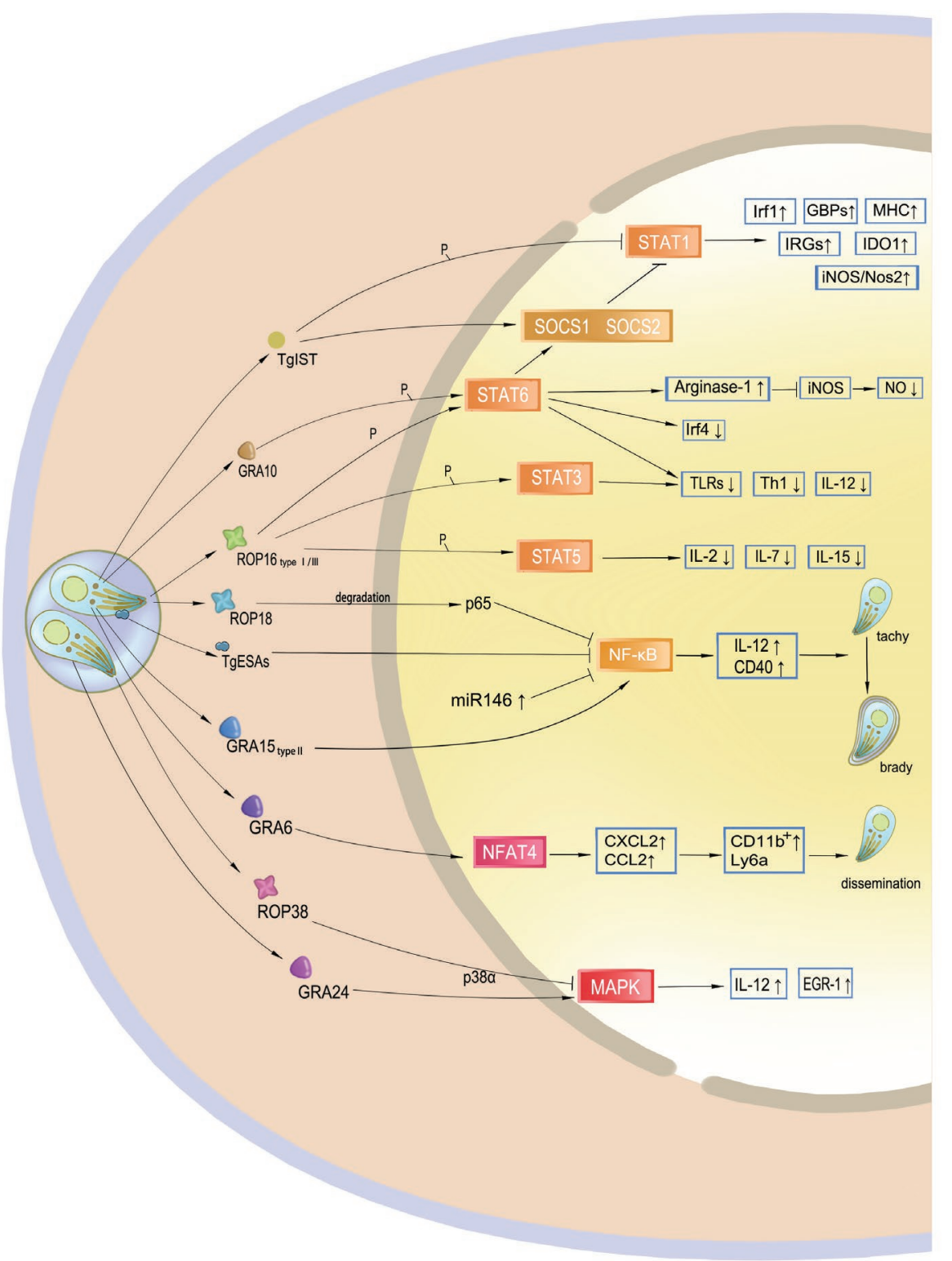

FIGURE 3 | Targeting of host gene expression by Toxoplasma gondii. Effectors secreted by T. gondii manipulate host gene expression. TgIST translocates to the nucleus after T. gondii invasion and inhibits STAT1 by phosphorylation. GRA10 and ROP16 phosphorylate STAT3 and STAT6, mainly leading to a decrease in IL-12 and Th1 response. Additionally, phosphorylation of STAT6 results in resistance to NO. ROP18 and TgESAs block the NF-кB signaling pathway and impair CD40and TNF-regulated parasite control of the host. However, GRA15 of type II activates this signaling pathway, which may promote cyst formation of the avirulent strain to avoid host immunity. GRA6 activates the host transcription factor NFAT4, and then attracts inflammatory cells and facilitates T. gondii dissemination. ROP38 and GRA24 have a diverse role in the modulation of the MAPK pathway.

(Ma et al., 2014). The p38 MAP kinase pathway controls gene expression and the early immune response, such as IL-12 production, to restrain T. gondii. GRA24 modulates host immune responses by triggering prolonged autophosphorylation and nuclear translocation of the host cell p38 MAPK (Braun et al., 2013). Interestingly, ROP38 has an adverse influence in downregulating MAPK signaling and some other transcriptional controls without affecting parasite replication and virulence (Peixoto et al., 2010). ROP38 functions in accordance with the demands of parasite survival, including bradyzoite differentiation, or maintaining the viability of the infected host cells. GRA16 is secreted and eventually exported to the host nucleus to interact with the herpesvirus-associated ubiquitin-specific protease (HAUSP) and modulate host gene expression, such as the p53 tumor suppressor pathway, which promotes host cell survival under stress conditions. The export of the GRA16 and GRA24 effectors into host cells and their accumulation in the nucleus are mediated by the aspartyl protease TgASP5 (Curt-Varesano et al., 2016). According to a recent study, ROP17 downregulates the activation of many immune signaling pathways and 
transcription factors to inhibit immune responses during $T$. gondii infection in human cells (Li et al., 2019).

\section{MODULATION OF HOST CELL SURVIVAL AND DEATH FOR PARASITE PROLIFERATION}

Intracellular $T$. gondii depends on the sustained life of host cells for its growth, metabolism, and proliferation. Host cell death seriously threatens parasite survival, whereas apoptosis induction in some cells may suppress the immune responses against the parasite (Luder et al., 2001). Modulation of host cell survival and death is one of the strategies for T. gondii survival (Figure 4).
Inhibition of host cell apoptosis may preserve intracellular replication and long-term survival of the parasite. T. gondii infection inhibits mitochondrial apoptosis by preventing the release of cytochrome-c and phosphorylation of the pro-apoptotic Bad protein and inducing overproduction of the anti-apoptotic Bcl-2 (Hippe et al., 2008; Hwang et al., 2010; Quan et al., 2013). In infected macrophages, $T$. gondii also induces serpin B3/B4 expression through STAT6 activation and activates the STAT3-miR-17-92-Bim pathway to inhibit apoptosis (Song et al., 2012; Cai et al., 2014). In addition to blockage of cytochrome-c release, T. gondii targets the holo-apoptosome assembly to inhibit caspase-dependent intrinsic cell death (Graumann et al., 2015). ROP18, an important virulence determinant of the parasite, has been found to play a role in regulating apoptosis of infected cells. It inhibits host cell apoptosis by blocking the release of cytochrome-c, upregulating the ratio

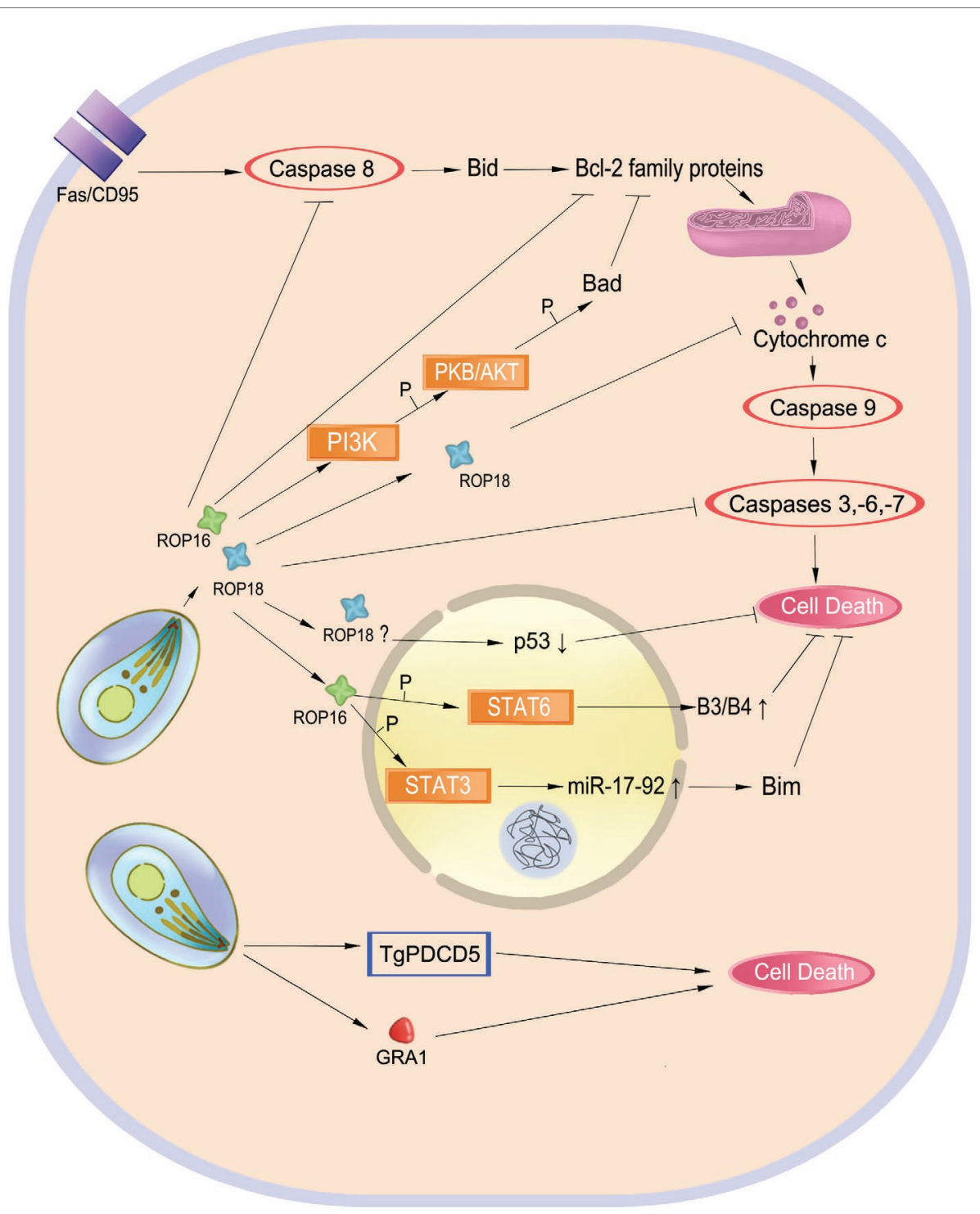

FIGURE 4 | Balancing host cell survival and death. Inhibition of cell apoptosis preserves the intracellular parasite Toxoplasma gondii. Effectors such as ROP18 play a role in Fas/CD95-mediated apoptosis to inhibit this process. ROP16 also phosphorylates STAT3 and STAT6 to inhibit cell death. However, TgPDCD5 and GRA1 induce cell death, which may help the parasite survive by killing host's immune cells. 
of Bcl-2/Bax, and inducing p53 degradation (Wu et al., 2016; Yang et al., 2017b; Xia et al., 2018).

On the other hand, induction or enhancement of apoptosis in the course of T. gondii infection might be beneficial for the parasite (Figure 4). Programmed cell death 5 (TgPDCD5), a protein released from T. gondii, enhances apoptosis of uninfected host macrophages, which appears to be a negative regulator of the immune response against the parasite (Bannai et al., 2008, 2009). Similarly, GRA1 secreted by T. gondii induces apoptosis of monocytes that is mediated by the TGF- $\beta$ pathway (Ngo et al., 2017). Apoptosis and cell death in bystander host cells may be caused by nitric oxide and other soluble factors produced by infected cells (Nishikawa et al., 2007).

\section{SURVIVAL STRATEGIES IN THE CHRONIC INFECTION STAGE}

After exponential replication as tachyzoites, the increasing host immune response and accompanying stress conditions lead T. gondii to differentiate into the latent bradyzoite stage that resides in tissue cysts. This stage allows the parasites to cause chronic disease owing to their ability to evade the immune system and resist common therapies. In addition, when the host immunity becomes impaired, T. gondii being an opportunistic pathogen may transform into rapidly replicating tachyzoites. Infectious bradyzoite cysts forming in muscle, heart, and central nervous system (CNS) tissues allow T. gondii to spread to a new host following predation of its former host, a part of the parasite's life cycle.

Because of the "Trojan horse" strategy in which tachyzoites move to immune-privileged organs such as the CNS and form cysts under the regulation of multiple genes, bradyzoites within tissue cysts persist for the life of their host (Hong et al., 2017; Huang et al., 2017). Rhoptry proteins such as ROP17, ROP35, and ROP38 also promote tachyzoite conversion to encysted bradyzoite. The persistent cyst is cloaked with a glycosylated structure called the cyst wall, which provides a sturdy barrier for bradyzoite survival and infectivity for oral transmission. Cyst wall glycoprotein CST1 glycosylated by Tg.ppGalNAc-Ts confers structural rigidity in brain cysts in a mucin-like domain-dependent manner (Tomita et al., 2013, 2017). A toxoplasma nucleotidesugar transporter (TgNST1) is also required for cyst wall glycosylation (Caffaro et al., 2013). Bradyzoite-secreted pseudokinase 1 (BPK1) is a component of the cyst wall and necessary for the growth, maintenance, and stability of tissue cysts (Buchholz et al., 2013). Several GRA proteins contribute to cyst wall formation and maintenance. A recent report demonstrated that the $T$. gondii lysosomal vacuolar compartment (TgVAC) is capable of proteolysis and maintains the viability and persistence of T. gondii cysts (Di Cristina et al., 2017).

\section{CONCLUDING REMARKS}

T. gondii is an intracellular parasite with an efficient invasion system that avoids phagocytosis. After a successful invasion, it secretes many different effectors to disturb the canonical
CD40-CD40L-mediated and the noncanonical IFN- $\gamma$-dependent autophagy, regulate host gene expression, modulate host cell survival and death, and counter host defense mechanisms. T. gondii needs a balance between establishing a successful infection in the host for ensuring propagation, and avoiding a too rapid multiplication that would kill the host. Additionally, as a successful intracellular parasite, obtaining nutrients from the host is also a critical survival strategy (for a more detailed discussion of nutrients, see Blume and Seeber (2018) and references therein). T. gondii employs different approaches in a strain-specific or host-specific manner to fight against different hosts. Striking differences in the strategies adopted by the parasite have been observed between murine and human hosts. Though anti-Toxoplasma responses have been extensively investigated in a mouse model, the mechanisms used by human cells to control the parasite and by the parasite to antagonize these responses remain elusive. For instance, what is the major IFN- $\gamma$ induced effector in human cells, as there are no IFN $\gamma$-inducible IRGs and a reduced GBP repertoire? What are the Toxoplasma virulence factors in humans, and how do they defend the PV from host destruction in human cells? As is known that ROP18 and ROP5 are the major virulence factors in strains from North America, Europe, and South America in mice, what are the virulent determinants in the atypical lineages (i.e., types 13/ Chinese 1 from China, 14 from Africa, and 11 from North America), and how do these determinants fight the immune system in mice and in humans to help the parasite survive? Addressing these questions will allow a better description of the battle between T. gondii and its hosts, and such knowledge will be useful in the development of drugs to control the parasite.

\section{AUTHOR CONTRIBUTIONS}

LY and JS designed the work. JL and WZ drafted the article. LY and FP did critical revision of the article. All authors read and approved the final version of the manuscript.

\section{FUNDING}

This work was supported by grants from the National Key R\&D Program of China (to LY, grant no. 2017YFD0500400) and Natural Science Foundation of China (to LY, grant no. 81572022, 81871671, and JS, grant no. 81471983), Key projects for supporting outstanding young talents in Universities in Anhui (to LY, grant no. gxyqZD2016044).

\section{ACKNOWLEDGMENTS}

The authors would like to thank members of our laboratories for many thoughtful discussions, and many thanks to Xinyuan $\mathrm{Li}$ (Reproductive Center of the First Affiliated Hospital of Anhui Medical University) for the art works. The authors also apologize to the many investigators whose contributions have not been mentioned owing to space limitations. 


\section{REFERENCES}

Ajzenberg, D., Banuls, A. L., Tibayrenc, M., and Darde, M. L. (2002). Microsatellite analysis of Toxoplasma gondii shows considerable polymorphism structured into two main clonal groups. Int. J. Parasitol. 32, 27-38. doi: 10.1016/ S0020-7519(01)00301-0

Alaganan, A., Fentress, S. J., Tang, K., Wang, Q., and Sibley, L. D. (2014). Toxoplasma GRA7 effector increases turnover of immunity-related GTPases and contributes to acute virulence in the mouse. Proc. Natl. Acad. Sci. U. S. A. 111, 1126-1131. doi: 10.1073/pnas.1313501111

Alexander, D. L., Mital, J., Ward, G. E., Bradley, P., and Boothroyd, J. C. (2005). Identification of the moving junction complex of Toxoplasma gondii: a collaboration between distinct secretory organelles. PLoS Pathog. 1:e17. doi: 10.1371 /journal.ppat.0010017

Aliberti, J. (2005). Host persistence: exploitation of anti-inflammatory pathways by Toxoplasma gondii. Nat. Rev. Immunol. 5, 162-170. doi: 10.1038/nri1547

Aliberti, J., Valenzuela, J. G., Carruthers, V. B., Hieny, S., Andersen, J., Charest, H., et al. (2003). Molecular mimicry of a CCR5 binding-domain in the microbial activation of dendritic cells. Nat. Immunol. 4, 485-490. doi: $10.1038 /$ ni915

Andrade, R. M., Wessendarp, M., Gubbels, M. J., Striepen, B., and Subauste, C. S. (2006). CD40 induces macrophage anti-Toxoplasma gondii activity by triggering autophagy-dependent fusion of pathogen-containing vacuoles and lysosomes. J. Clin. Invest. 116, 2366-2377. doi: 10.1172/jci28796

Ayoade, F., Todd, J., Al-Delfi, F., and King, J. (2017). Extensive brain masses and cavitary lung lesions associated with toxoplasmosis and acquired immunodeficiency syndrome. Int. J. STD AIDS 28, 1150-1154. doi: $10.1177 / 0956462417696216$

Bando, H., Lee, Y., Sakaguchi, N., Pradipta, A., Ma, J. S., Tanaka, S., et al. (2018). Inducible nitric oxide synthase is a key host factor for Toxoplasma GRA15-dependent disruption of the gamma interferon-induced antiparasitic human response. MBio 9:e01738-18. doi: 10.1128/mBio.01738-18

Bannai, H., Nishikawa, Y., Ibrahim, H. M., Yamada, K., Kawase, O., Watanabe, J., et al. (2009). Overproduction of the pro-apoptotic molecule, programmed cell death 5, in Toxoplasma gondii leads to increased apoptosis of host macrophages. J. Vet. Med. Sci. 71, 1183-1189. doi: 10.1292/jvms.71.1183

Bannai, H., Nishikawa, Y., Matsuo, T., Kawase, O., Watanabe, J., Sugimoto, C., et al. (2008). Programmed cell death 5 from Toxoplasma gondii: a secreted molecule that exerts a pro-apoptotic effect on host cells. Mol. Biochem. Parasitol. 159, 112-120. doi: 10.1016/j.molbiopara.2008.02.012

Bekpen, C., Hunn, J. P., Rohde, C., Parvanova, I., Guethlein, L., Dunn, D. M., et al. (2005). The interferon-inducible p47 (IRG) GTPases in vertebrates: loss of the cell autonomous resistance mechanism in the human lineage. Genome Biol. 6:R92. doi: 10.1186/gb-2005-6-11-r92

Besteiro, S. (2018). The role of host autophagy machinery in controlling Toxoplasma infection. Virulence 1-10. doi: 10.1080/21505594.2018.1518102

Besteiro, S., Michelin, A., Poncet, J., Dubremetz, J. F., and Lebrun, M. (2009). Export of a Toxoplasma gondii rhoptry neck protein complex at the host cell membrane to form the moving junction during invasion. PLoS Pathog. 5:e1000309. doi: 10.1371/journal.ppat.1000309

Blume, M., and Seeber, F. (2018). Metabolic interactions between Toxoplasma gondii and its host. F1000Res 7, 1719-1728. doi: 10.12688/f1000research.16021.1

Boucher, L. E., and Bosch, J. (2015). The apicomplexan glideosome and adhesinsstructures and function. J. Struct. Biol. 190, 93-114. doi: 10.1016/j. jsb.2015.02.008

Braun, L., Brenier-Pinchart, M. P., Yogavel, M., Curt-Varesano, A., Curt-Bertini, R. L., Hussain, T., et al. (2013). A Toxoplasma dense granule protein, GRA24, modulates the early immune response to infection by promoting a direct and sustained host p38 MAPK activation. J. Exp. Med. 210, 2071-2086. doi: 10.1084/jem.20130103

Buchholz, K. R., Bowyer, P. W., and Boothroyd, J. C. (2013). Bradyzoite pseudokinase 1 is crucial for efficient oral infectivity of the Toxoplasma gondii tissue cyst. Eukaryot. Cell 12, 399-410. doi: 10.1128/EC.00343-12

Caffaro, C. E., Koshy, A. A., Liu, L., Zeiner, G. M., Hirschberg, C. B., and Boothroyd, J. C. (2013). A nucleotide sugar transporter involved in glycosylation of the Toxoplasma tissue cyst wall is required for efficient persistence of bradyzoites. PLoS Pathog. 9:e1003331. doi: 10.1371/journal. ppat.1003331
Cai, Y., Chen, H., Mo, X., Tang, Y., Xu, X., Zhang, A., et al. (2014). Toxoplasma gondii inhibits apoptosis via a novel STAT3-miR-17-92-Bim pathway in macrophages. Cell. Signal. 26, 1204-1212. doi: 10.1016/j.cellsig.2014.02.013

Cavailles, P., Flori, P., Papapietro, O., Bisanz, C., Lagrange, D., Pilloux, L., et al. (2014). A highly conserved Toxol haplotype directs resistance to toxoplasmosis and its associated caspase-1 dependent killing of parasite and host macrophage. PLoS Pathog. 10:e1004005. doi: 10.1371/journal.ppat.1004005

Cavailles, P., Sergent, V., Bisanz, C., Papapietro, O., Colacios, C., Mas, M., et al. (2006). The rat Toxol locus directs toxoplasmosis outcome and controls parasite proliferation and spreading by macrophage-dependent mechanisms. Proc. Natl. Acad. Sci. U. S. A. 103, 744-749. doi: 10.1073/pnas.0506643103

Ceravolo, I. P., Chaves, A. C., Bonjardim, C. A., Sibley, D., Romanha, A. J., and Gazzinelli, R. T. (1999). Replication of Toxoplasma gondii, but not Trypanosoma cruzi, is regulated in human fibroblasts activated with gamma interferon: requirement of a functional JAK/STAT pathway. Infect. Immun. 67, 2233-2240.

Chang, S., Shan, X., Li, X., Fan, W., Zhang, S. Q., Zhang, J., et al. (2015). Toxoplasma gondii rhoptry protein ROP16 mediates partially SH-SY5Y cells apoptosis and cell cycle arrest by directing Ser15/37 phosphorylation of p53. Int. J. Biol. Sci. 11, 1215-1225. doi: 10.7150/ijbs.10516

Chen, Z. W., Gao, J. M., Huo, X. X., Wang, L., Yu, L., Halm-Lai, F., et al. (2011). Genotyping of Toxoplasma gondii isolates from cats in different geographic regions of China. Vet. Parasitol. 183, 166-170. doi: 10.1016/j. vetpar.2011.06.013

Cirelli, K. M., Gorfu, G., Hassan, M. A., Printz, M., Crown, D., Leppla, S. H., et al. (2014). Inflammasome sensor NLRP1 controls rat macrophage susceptibility to Toxoplasma gondii. PLoS Pathog. 10:e1003927. doi: 10.1371/ journal.ppat. 1003927

Clough, B., and Frickel, E. M. (2017). The Toxoplasma parasitophorous vacuole: an evolving host-parasite Frontier. Trends Parasitol. 33, 473-488. doi: 10.1016/j. pt.2017.02.007

Curt-Varesano, A., Braun, L., Ranquet, C., Hakimi, M. A., and Bougdour, A. (2016). The aspartyl protease TgASP5 mediates the export of the Toxoplasma GRA16 and GRA24 effectors into host cells. Cell. Microbiol. 18, 151-167. doi: $10.1111 / \mathrm{cmi} .12498$

Darde, M. L., Bouteille, B., and Pestre-Alexandre, M. (1992). Isoenzyme analysis of 35 Toxoplasma gondii isolates and the biological and epidemiological implications. J. Parasitol. 78, 786-794. doi: 10.2307/3283305

Deretic, V., Saitoh, T., and Akira, S. (2013). Autophagy in infection, inflammation and immunity. Nat. Rev. Immunol. 13, 722-737. doi: 10.1038/nri3532

Deter, R. L., Baudhuin, P., and De Duve, C. (1967). Participation of lysosomes in cellular autophagy induced in rat liver by glucagon. J. Cell Biol. 35, C11-C16. doi: 10.1083/jcb.35.2.C11

Di Cristina, M., Dou, Z., Lunghi, M., Kannan, G., Huynh, M. H., McGovern, O. L., et al. (2017). Toxoplasma depends on lysosomal consumption of autophagosomes for persistent infection. Nat. Microbiol. 2:17096. doi: 10.1038/ nmicrobiol.2017.96

Du, J., An, R., Chen, L., Shen, Y., Chen, Y., Cheng, L., et al. (2014). Toxoplasma gondii virulence factor ROP18 inhibits the host NF-kappaB pathway by promoting p65 degradation. J. Biol. Chem. 289, 12578-12592. doi: 10.1074/ jbc.M113.544718

Dubey, J. P. (2010). Toxoplasmosis of animals and humans. 2nd edn. (Boca Raton, Florida: CRC Press).

Dubey, J. P., Ferreira, L. R., Alsaad, M., Verma, S. K., Alves, D. A., Holland, G. N., et al. (2016). Experimental toxoplasmosis in rats induced orally with eleven strains of Toxoplasma gondii of seven genotypes: tissue tropism, tissue cyst size, neural lesions, tissue cyst rupture without reactivation, and ocular lesions. PLoS One 11:e0156255. doi: 10.1371/journal.pone.0156255

Etheridge, R. D., Alaganan, A., Tang, K., Lou, H. J., Turk, B. E., and Sibley, L. D. (2014). The Toxoplasma pseudokinase ROP5 forms complexes with ROP18 and ROP17 kinases that synergize to control acute virulence in mice. Cell Host Microbe 15, 537-550. doi: 10.1016/j.chom.2014.04.002

Frenal, K., Polonais, V., Marq, J. B., Stratmann, R., Limenitakis, J., and Soldati-Favre, D. (2010). Functional dissection of the apicomplexan glideosome molecular architecture. Cell Host Microbe 8, 343-357. doi: 10.1016/j. chom.2010.09.002

Gay, G., Braun, L., Brenier-Pinchart, M. P., Vollaire, J., Josserand, V., Bertini, R. L., et al. (2016). Toxoplasma gondii TgIST co-opts host chromatin repressors 
dampening STAT1-dependent gene regulation and IFN-gamma-mediated host defenses. J. Exp. Med. 213, 1779-1798. doi: 10.1084/jem.20160340

Gold, D. A., Kaplan, A. D., Lis, A., Bett, G. C., Rosowski, E. E., Cirelli, K. M., et al. (2015). The Toxoplasma dense granule proteins GRA17 and GRA23 mediate the movement of small molecules between the host and the parasitophorous vacuole. Cell Host Microbe 17, 642-652. doi: 10.1016/j. chom.2015.04.003

Gras, S., Jackson, A., Woods, S., Pall, G., Whitelaw, J., Leung, J. M., et al. (2017). Parasites lacking the micronemal protein MIC2 are deficient in surface attachment and host cell egress, but remain virulent in vivo. Wellcome Open Res. 2:32. doi: 10.12688/wellcomeopenres.11594.1

Graumann, K., Schaumburg, F., Reubold, T. F., Hippe, D., Eschenburg, S., and Luder, C. G. (2015). Toxoplasma gondii inhibits cytochrome c-induced caspase activation in its host cell by interference with holo-apoptosome assembly. Microb Cell 2, 150-162. doi: 10.15698/mic2015.05.201

Guerin, A., El Hajj, H., Penarete-Vargas, D., Besteiro, S., and Lebrun, M. (2017). RON4L1 is a new member of the moving junction complex in Toxoplasma gondii. Sci. Rep. 7:17907. doi: 10.1038/s41598-017-18010-9

Hakimi, M. A., Olias, P., and Sibley, L. D. (2017). Toxoplasma effectors targeting host signaling and transcription. Clin. Microbiol. Rev. 30, 615-645. doi: 10.1128/cmr.00005-17

Haldar, A. K., Piro, A. S., Pilla, D. M., Yamamoto, M., and Coers, J. (2014). The E2-like conjugation enzyme Atg3 promotes binding of IRG and Gbp proteins to Chlamydia- and Toxoplasma-containing vacuoles and host resistance. PLoS One 9:e86684. doi: 10.1371/journal.pone.0086684

Hermanns, T., Muller, U. B., Konen-Waisman, S., Howard, J. C., and Steinfeldt, T. (2016). The Toxoplasma gondii rhoptry protein ROP18 is an Irga6-specific kinase and regulated by the dense granule protein GRA7. Cell. Microbiol. 18, 244-259. doi: $10.1111 / \mathrm{cmi} .12499$

Herm-Gotz, A., Weiss, S., Stratmann, R., Fujita-Becker, S., Ruff, C., Meyhofer, E., et al. (2002). Toxoplasma gondii myosin A and its light chain: a fast, singleheaded, plus-end-directed motor. EMBO J. 21, 2149-2158. doi: 10.1093/ emboj/21.9.2149

Hippe, D., Lytovchenko, O., Schmitz, I., and Luder, C. G. (2008). Fas/CD95mediated apoptosis of type II cells is blocked by Toxoplasma gondii primarily via interference with the mitochondrial amplification loop. Infect. Immun. 76, 2905-2912. doi: 10.1128/IAI.01546-07

Hong, D. P., Radke, J. B., and White, M. W. (2017). Opposing transcriptional mechanisms regulate Toxoplasma development. mSphere 2:e00347. doi: 10.1128/ mSphere.00347-16

Howard, J. C., Hunn, J. P., and Steinfeldt, T. (2011). The IRG proteinbased resistance mechanism in mice and its relation to virulence in Toxoplasma gondii. Curr. Opin. Microbiol. 14, 414-421. doi: 10.1016/j. mib.2011.07.002

Howe, D. K., Honore, S., Derouin, F., and Sibley, L. D. (1997). Determination of genotypes of Toxoplasma gondii strains isolated from patients with toxoplasmosis. J. Clin. Microbiol. 35, 1411-1414.

Howe, D. K., and Sibley, L. D. (1995). Toxoplasma gondii comprises three clonal lineages: correlation of parasite genotype with human disease. J. Infect. Dis. 172, 1561-1566. doi: 10.1093/infdis/172.6.1561

Huang, S., Holmes, M. J., Radke, J. B., Hong, D. P., Liu, T. K., White, M. W., et al. (2017). Toxoplasma gondii AP2IX-4 regulates gene expression during bradyzoite development. $m$ Sphere 2:e00054. doi: 10.1128/mSphere.00054-17

Hwang, I. Y., Quan, J. H., Ahn, M. H., Ahmed, H. A., Cha, G. H., Shin, D. W., et al. (2010). Toxoplasma gondii infection inhibits the mitochondrial apoptosis through induction of Bcl-2 and HSP70. Parasitol. Res. 107, 1313-1321. doi: 10.1007/s00436-010-1999-3

Jacot, D., Tosetti, N., Pires, I., Stock, J., Graindorge, A., Hung, Y. F., et al. (2016). An apicomplexan actin-binding protein serves as a connector and lipid sensor to coordinate motility and invasion. Cell Host Microbe 20, 731-743. doi: 10.1016/j.chom.2016.10.020

Jewett, T. J., and Sibley, L. D. (2003). Aldolase forms a bridge between cell surface adhesins and the actin cytoskeleton in apicomplexan parasites. Mol. Cell 11, 885-894. doi: 10.1016/S1097-2765(03)00113-8

Johnston, A. C., Piro, A., Clough, B., Siew, M., Virreira Winter, S., Coers, J., et al. (2016). Human GBP1 does not localize to pathogen vacuoles but restricts Toxoplasma gondii. Cell. Microbiol. 18, 1056-1064. doi: 10.1111/ cmi. 12579
Kim, J., Kundu, M., Viollet, B., and Guan, K. L. (2011). AMPK and mTOR regulate autophagy through direct phosphorylation of Ulk1. Nat. Cell Biol. 13, 132-141. doi: 10.1038/ncb2152

Kim, J. H., Lee, J., Bae, S. J., Kim, Y., Park, B. J., Choi, J. W., et al. (2017). NADPH oxidase 4 is required for the generation of macrophage migration inhibitory factor and host defense against Toxoplasma gondii infection. Sci. Rep. 7:6361. doi: 10.1038/s41598-017-06610-4

Koblansky, A. A., Jankovic, D., Oh, H., Hieny, S., Sungnak, W., Mathur, R., et al. (2013). Recognition of profilin by toll-like receptor 12 is critical for host resistance to Toxoplasma gondii. Immunity 38, 119-130. doi: 10.1016/j. immuni.2012.09.016

Kwok, L. Y., Schlüter, D., Clayton, C., and Soldati, D. (2003). The antioxidant systems in Toxoplasma gondii and the role of cytosolic catalase in defence against oxidative injury. Mol. Microbiol. 51, 47-61. doi: 10.1046/j.1365-2958.2003.03823.x

Lai, S. C., and Devenish, R. J. (2012). LC3-associated phagocytosis (LAP): connections with host autophagy. Cell 1, 396-408. doi: 10.3390/cells1030396

Lamarque, M., Besteiro, S., Papoin, J., Roques, M., Vulliez-Le Normand, B., Morlon-Guyot, J., et al. (2011). The RON2-AMA1 interaction is a critical step in moving junction-dependent invasion by apicomplexan parasites. PLoS Pathog. 7:e1001276. doi: 10.1371/journal.ppat.1001276

Lamarque, M. H., Roques, M., Kong-Hap, M., Tonkin, M. L., Rugarabamu, G., Marq, J. B., et al. (2014). Plasticity and redundancy among AMA-RON pairs ensure host cell entry of Toxoplasma parasites. Nat. Commun. 5:4098. doi: $10.1038 /$ ncomms5098

Lebrun, M., Michelin, A., El Hajj, H., Poncet, J., Bradley, P. J., Vial, H., et al. (2005). The rhoptry neck protein RON4 re-localizes at the moving junction during Toxoplasma gondii invasion. Cell. Microbiol. 7, 1823-1833. doi: 10.1111/j.1462-5822.2005.00646.x

Li, J. X., He, J. J., Elsheikha, H. M., Chen, D., Zhai, B. T., Zhu, X. Q., et al. (2019). Toxoplasma gondii ROP17 inhibits the innate immune response of HEK293T cells to promote its survival. Parasitol. Res. 118, 783-792. doi: 10.1007/s00436-019-06215-y

Li, M., Mo, X. W., Wang, L., Chen, H., Luo, Q. L., Wen, H. Q., et al. (2014). Phylogeny and virulence divergency analyses of Toxoplasma gondii isolates from China. Parasit. Vectors 7:133. doi: 10.1186/1756-3305-7-133

Liu, E., Lopez Corcino, Y., Portillo, J. A., Miao, Y., and Subauste, C. S. (2016). Identification of signaling pathways by which CD40 stimulates autophagy and antimicrobial activity against Toxoplasma gondii in macrophages. Infect. Immun. 84, 2616-2626. doi: 10.1128/IAI.00101-16

Luder, C. G., Gross, U., and Lopes, M. F. (2001). Intracellular protozoan parasites and apoptosis: diverse strategies to modulate parasite-host interactions. Trends Parasitol. 17, 480-486. doi: 10.1016/S1471-4922(01)02016-5

Ma, J. S., Sasai, M., Ohshima, J., Lee, Y., Bando, H., Takeda, K., et al. (2014). Selective and strain-specific NFAT4 activation by the Toxoplasma gondii polymorphic dense granule protein GRA6. J. Exp. Med. 211, 2013-2032. doi: $10.1084 /$ jem. 20131272

Matta, S. K., Patten, K., Wang, Q., Kim, B. H., MacMicking, J. D., and Sibley, L. D. (2018). NADPH oxidase and guanylate binding protein 5 restrict survival of avirulent type III strains of Toxoplasma gondii in naive macrophages. MBio 9:e01393. doi: 10.1128/mBio.01393-18

Meissner, M., Reiss, M., Viebig, N., Carruthers, V. B., Toursel, C., Tomavo, S., et al. (2002a). A family of transmembrane microneme proteins of Toxoplasma gondii contain EGF-like domains and function as escorters. J. Cell Sci. 115, 563-574. doi: 10.1116/1.584155

Meissner, M., Schluter, D., and Soldati, D. (2002b). Role of Toxoplasma gondii myosin A in powering parasite gliding and host cell invasion. Science 298, 837-840. doi: 10.1126/science.1074553

Mizushima, N., Yoshimori, T., and Ohsumi, Y. (2011). The role of Atg proteins in autophagosome formation. Annu. Rev. Cell Dev. Biol. 27, 107-132. doi: 10.1146/annurev-cellbio-092910-154005

Mordue, D., and Sibley, D. (1997). Intracellular fate of vacuoles containing Toxoplasma gondii is determined at the time of formation and depends on the mechanism of entry. J. Immunol. 9, 4452-4459.

Morgado, P., Sudarshana, D. M., Gov, L., Harker, K. S., Lam, T., Casali, P., et al. (2014). Type II Toxoplasma gondii induction of CD40 on infected macrophages enhances interleukin-12 responses. Infect. Immun. 82, 4047-4055. doi: 10.1128/IAI.01615-14 
Moroda, M., Takamoto, M., Iwakura, Y., Nakayama, J., and Aosai, F. (2017). Interleukin-17A-deficient mice are highly susceptible to Toxoplasma gondii infection due to excessively induced T. gondii HSP70 and interferon gamma production. Infect. Immun. 85:e0399-17. doi: 10.1128/IAI.00399-17

Muniz-Feliciano, L., Van Grol, J., Portillo, J. A., Liew, L., Liu, B., Carlin, C. R., et al. (2013). Toxoplasma gondii-induced activation of EGFR prevents autophagy protein-mediated killing of the parasite. PLoS Pathog. 9:e1003809. doi: 10.1371/ journal.ppat.1003809

Nagineni, C. N., Pardhasaradhi, K., Martins, M. C., Detrick, B., and Hooks, J. J. (1996). Mechanisms of interferon-induced inhibition of Toxoplasma gondii replication in human retinal pigment epithelial cells. Infect. Immun. 64, 4188-4196.

Ngo, H. M., Zhou, Y., Lorenzi, H., Wang, K., Kim, T. K., Zhou, Y., et al. (2017). Toxoplasma modulates signature pathways of human epilepsy, neurodegeneration \& cancer. Sci. Rep. 7:11496. doi: 10.1038/s41598-017-10675-6

Niedelman, W., Gold, D. A., Rosowski, E. E., Sprokholt, J. K., Lim, D., Farid Arenas, A., et al. (2012). The rhoptry proteins ROP18 and ROP5 mediate Toxoplasma gondii evasion of the murine, but not the human, interferon-gamma response. PLoS Pathog. 8:e1002784. doi: 10.1371/journal. ppat.1002784

Nishikawa, Y., Kawase, O., Vielemeyer, O., Suzuki, H., Joiner, K. A., Xuan, X., et al. (2007). Toxoplasma gondii infection induces apoptosis in noninfected macrophages: role of nitric oxide and other soluble factors. Parasite Immunol. 29, 375-385. doi: 10.1111/j.1365-3024.2007.00956.x

Ohshima, J., Lee, Y., Sasai, M., Saitoh, T., Su Ma, J., Kamiyama, N., et al. (2014). Role of mouse and human autophagy proteins in IFN-gamma-induced cell-autonomous responses against Toxoplasma gondii. J. Immunol. 192, 3328-3335. doi: 10.4049/jimmunol.1302822

Ohsumi, Y. (2014). Historical landmarks of autophagy research. Cell Res. 24, 9-23. doi: 10.1038/cr.2013.169

Olias, P., Etheridge, R. D., Zhang, Y., Holtzman, M. J., and Sibley, L. D. (2016). Toxoplasma effector recruits the Mi-2/NuRD complex to repress STAT1 transcription and block IFN-gamma-dependent gene expression. Cell Host Microbe 20, 72-82. doi: 10.1016/j.chom.2016.06.006

Padrao Jda, C., Cabral, G. R., da Silva Mde, F., Seabra, S. H., and DaMatta, R. A. (2014). Toxoplasma gondii infection of activated J774-A1 macrophages causes inducible nitric oxide synthase degradation by the proteasome pathway. Parasitol. Int. 63, 659-663. doi: 10.1016/j.parint.2014.05.003

Parker, M. L., Penarete-Vargas, D. M., Hamilton, P. T., Guerin, A., Dubey, J. P., Perlman, S. J., et al. (2016). Dissecting the interface between apicomplexan parasite and host cell: insights from a divergent AMA-RON2 pair. Proc. Natl. Acad. Sci. U. S. A. 113, 398-403. doi: 10.1073/pnas.1515898113

Pavlou, G., Biesaga, M., Touquet, B., Lagal, V., Balland, M., Dufour, A., et al. (2018). Toxoplasma parasite twisting motion mechanically induces host cell membrane fission to complete invasion within a protective vacuole. Cell Host Microbe 24, 81-96.e85. doi: 10.1016/j.chom.2018.06.003

Peixoto, L., Chen, F., Harb, O. S., Davis, P. H., Beiting, D. P., Brownback, C. S., et al. (2010). Integrative genomic approaches highlight a family of parasitespecific kinases that regulate host responses. Cell Host Microbe 8, 208-218. doi: 10.1016/j.chom.2010.07.004

Pfefferkorn, E. R., Eckel, M., and Rebhun, S. (1986). Interferon-gamma suppresses the growth of Toxoplasma gondii in human fibroblasts through starvation for tryptophan. Mol. Biochem. Parasitol. 20, 215-224. doi: 10.1016/0166-6851(86)90101-5

Pino, P., Foth, B. J., Kwok, L. Y., Sheiner, L., Schepers, R., Soldati, T., et al. (2007). Dual targeting of antioxidant and metabolic enzymes to the mitochondrion and the apicoplast of Toxoplasma gondii. PLoS Pathog. 3:e115. doi: 10.1371/journal.ppat.0030115

Portillo, J. C., Muniz-Feliciano, L., Lopez Corcino, Y., Lee, S. J., Van Grol, J., Parsons, S. J., et al. (2017). Toxoplasma gondii induces FAK-Src-STAT3 signaling during infection of host cells that prevents parasite targeting byautophagy. PLoS Pathog. 13:e1006671. doi: 10.1371/journal.ppat.1006671

Portillo, J. A., Okenka, G., Reed, E., Subauste, A., Van Grol, J., Gentil, K., et al. (2010). The CD40-autophagy pathway is needed for host protection despite IFN-gamma-dependent immunity and CD40 induces autophagy via control of P21 levels. PLoS One 5:e14472. doi: 10.1371/journal.pone.0014472

Poukchanski, A., Fritz, H. M., Tonkin, M. L., Treeck, M., Boulanger, M. J., and Boothroyd, J. C. (2013). Toxoplasma gondii sporozoites invade host cells using two novel paralogues of RON2 and AMA1. PLoS One 8:e70637. doi: 10.1371/journal.pone.0070637
Quan, J. H., Cha, G. H., Zhou, W., Chu, J. Q., Nishikawa, Y., and Lee, Y. H. (2013). Involvement of PI 3 kinase/Akt-dependent Bad phosphorylation in Toxoplasma gondii-mediated inhibition of host cell apoptosis. Exp. Parasitol. 133, 462-471. doi: 10.1016/j.exppara.2013.01.005

Rabenau, K. E., Sohrabi, A., Tripathy, A., Reitter, C., Ajioka, J. W., Tomley, F. M., et al. (2001). TgM2AP participates in Toxoplasma gondii invasion of host cells and is tightly associated with the adhesive protein TgMIC2. Mol. Microbiol. 41, 537-547. doi: 10.1046/j.1365-2958.2001.02513.x

Roach, J. C., Glusman, G., Rowen, L., Kaur, A., Purcell, M. K., Smith, K. D., et al. (2005). The evolution of vertebrate toll-like receptors. Proc. Natl. Acad. Sci. U. S. A. 102, 9577-9582. doi: 10.1073/pnas.0502272102

Rosowski, E. E., and Saeij, J. P. (2012). Toxoplasma gondii clonal strains all inhibit STAT1 transcriptional activity but polymorphic effectors differentially modulate IFNgamma induced gene expression and STAT1 phosphorylation. PLoS One 7:e51448. doi: 10.1371/journal.pone.0051448

Safronova, A., Araujo, A., Camanzo, E. T., Moon, T. J., Elliott, M. R., Beiting, D. P., et al. (2019). Alarmin S100A11 initiates a chemokine response to the human pathogen Toxoplasma gondii. Nat. Immunol. 20, 64-72. doi: 10.1038/ s41590-018-0250-8

Sasai, M., Sakaguchi, N., Ma, J. S., Nakamura, S., Kawabata, T., Bando, H., et al. (2017). Essential role for GABARAP autophagy proteins in interferon-inducible GTPase-mediated host defense. Nat. Immunol. 18, 899-910. doi: 10.1038/ni.3767

Selleck, E. M., Orchard, R. C., Lassen, K. G., Beatty, W. L., Xavier, R. J., Levine, B., et al. (2015). A noncanonical autophagy pathway restricts Toxoplasma gondii growth in a strain-specific manner in IFN-gamma-activated human cells. MBio 6, e01157-e01115. doi: 10.1128/mBio.01157-15

Sergent, V., Cautain, B., Khalife, J., Deslee, D., Bastien, P., Dao, A., et al. (2005). Innate refractoriness of the Lewis rat to toxoplasmosis is a dominant trait that is intrinsic to bone marrow-derived cells. Infect. Immun. 73, 6990-6997. doi: 10.1128/iai.73.10.6990-6997.2005

Sibley, L. D., and Boothroyd, J. C. (1992). Virulent strains of Toxoplasma gondii comprise a single clonal lineage. Nature 359, 82-85. doi: 10.1038/359082a0

Sibley, L. D., Khan, A., Ajioka, J. W., and Rosenthal, B. M. (2009). Genetic diversity of Toxoplasma gondii in animals and humans. Philos. Trans. $R$. Soc. Lond. Ser. B Biol. Sci. 364, 2749-2761. doi: 10.1098/rstb.2009.0087

Soldati, D., Dubremetz, J. F., and Lebrun, M. (2001). Microneme proteins: structural and functional requirements to promote adhesion and invasion by the apicomplexan parasite Toxoplasma gondii. Int. J. Parasitol. 31, 1293-1302. doi: 10.1016/S0020-7519(01)00257-0

Song, K. J., Ahn, H. J., and Nam, H. W. (2012). Anti-apoptotic effects of SERPIN B3 and B4 via STAT6 activation in macrophages after infection with Toxoplasma gondii. Korean J. Parasitol. 50, 1-6. doi: 10.3347/kjp.2012.50.1.1

Tahara, M., Andrabi, S. B., Matsubara, R., Aonuma, H., and Nagamune, K. (2016). A host cell membrane microdomain is a critical factor for organelle discharge by Toxoplasma gondii. Parasitol. Int. 65, 378-388. doi: 10.1016/j. parint.2016.05.012

Tomita, T., Bzik, D. J., Ma, Y. F., Fox, B. A., Markillie, L. M., Taylor, R. C., et al. (2013). The Toxoplasma gondii cyst wall protein CST1 is critical for cyst wall integrity and promotes bradyzoite persistence. PLoS Pathog. 9:e1003823. doi: 10.1371/journal.ppat.1003823

Tomita, T., Sugi, T., Yakubu, R., Tu, V., Ma, Y., and Weiss, L. M. (2017). Making home sweet and sturdy: Toxoplasma gondii ppGalNAc-Ts glycosylate in hierarchical order and confer cyst wall rigidity. MBio 8:e02048-16. doi: 10.1128/mBio.02048-16

Tonkin, M. L., Roques, M., Lamarque, M. H., Pugniere, M., Douguet, D., Crawford, J., et al. (2011). Host cell invasion by apicomplexan parasites: insights from the co-structure of AMA1 with a RON2 peptide. Science 333, 463-467. doi: 10.1126/science.1204988

Tyler, J. S., and Boothroyd, J. C. (2011). The C-terminus of Toxoplasma RON2 provides the crucial link between AMA1 and the host-associated invasion complex. PLoS Pathog. 7:e1001282. doi: 10.1371/journal.ppat.1001282

Van Grol, J., Muniz-Feliciano, L., Portillo, J. A., Bonilha, V. L., and Subauste, C. S. (2013). CD40 induces anti-Toxoplasma gondii activity in nonhematopoietic cells dependent on autophagy proteins. Infect. Immun. 81, 2002-2011. doi: 10.1128/iai.01145-12

Wang, L., Chen, H., Liu, D., Huo, X., Gao, J., Song, X., et al. (2013). Genotypes and mouse virulence of Toxoplasma gondii isolates from animals and humans in China. PLoS One 8:e53483. doi: 10.1371/journal.pone.0053483 
Wang, Y., Cirelli, K. M., Barros, P. D. C., Sangare, L. O., Butty, V., Hassan, M. A., et al. (2019). Three Toxoplasma gondii dense granule proteins are required for induction of Lewis rat macrophage pyroptosis. MBio 10:e02388-18. doi: 10.1128/mBio.02388-18

Wang, Y., Fang, R., Yuan, Y., Pan, M., Hu, M., Zhou, Y., et al. (2016). Identification of host proteins, Spata3 and Dkk2, interacting with Toxoplasma gondii micronemal protein MIC3. Parasitol. Res. 115, 2825-2835. doi: 10.1007/ s00436-016-5033-2

Wang, S., Hassan, I. A., Liu, X., Xu, L., Yan, R., Song, X., et al. (2015). Immunological changes induced by Toxoplasma gondii glutathione-S-transferase (TgGST) delivered as a DNA vaccine. Res. Vet. Sci. 99, 157-164. doi: 10.1016/j. rvsc.2014.12.006

Wang, Y., and Yin, H. (2015). Research advances in microneme protein 3 of Toxoplasma gondii. Parasit. Vectors 8:384. doi: 10.1186/s13071-015-1001-4

Wang, S., Zhang, Z., Wang, Y., Gadahi, J. A., Xie, Q., Xu, L., et al. (2017). Toxoplasma gondii excretory/secretory antigens (TgESAs) suppress proinflammatory cytokine secretion by inhibiting TLR-induced NF-kappaB activation in LPS-stimulated murine macrophages. Oncotarget 8, 88351-88359. doi: 10.18632/oncotarget.19362

Wu, L., Wang, X., Li, Y., Liu, Y., Su, D., Fu, T., et al. (2016). Toxoplasma gondii ROP18: potential to manipulate host cell mitochondrial apoptosis. Parasitol. Res. 115, 2415-2422. doi: 10.1007/s00436-016-4993-6

Xia, J., Kong, L., Zhou, L. J., Wu, S. Z., Yao, L. J., He, C., et al. (2018). Genome-wide bimolecular fluorescence complementation-based proteomic analysis of Toxoplasma gondii ROP18's human interactome shows its key role in regulation of cell immunity and apoptosis. Front. Immunol. 9:61. doi: 10.3389/fimmu.2018.00061

Xue, J., Jiang, W., Chen, Y., Gong, F., Wang, M., Zeng, P., et al. (2017). Thioredoxin reductase from Toxoplasma gondii: an essential virulence effector with antioxidant function. FASEB J. 31, 4447-4457. doi: 10.1096/ f. $201700008 \mathrm{R}$

Yamamoto, M., Ma, J. S., Mueller, C., Kamiyama, N., Saiga, H., Kubo, E., et al. (2011). ATF6beta is a host cellular target of the Toxoplasma gondii virulence factor ROP18. J. Exp. Med. 208, 1533-1546. doi: 10.1084/ jem. 20101660

Yamamoto, M., Standley, D. M., Takashima, S., Saiga, H., Okuyama, M., Kayama, H., et al. (2009). A single polymorphic amino acid on Toxoplasma gondii kinase
ROP16 determines the direct and strain-specific activation of Stat3. J. Exp. Med. 206, 2747-2760. doi: 10.1084/jem.20091703

Yamamoto, M., and Takeda, K. (2012). Inhibition of ATF6beta-dependent host adaptive immune response by a Toxoplasma virulence factor ROP18. Virulence 3, 77-80. doi: 10.4161/viru.3.1.18340

Yang, Z., Hou, Y., Hao, T., Rho, H. S., Wan, J., Luan, Y., et al. (2017b). A human proteome array approach to identifying key host proteins targeted by Toxoplasma kinase ROP18. Mol. Cell. Proteomics 16, 469-484. doi: 10.1074/ mcp.M116.063602

Yang, W. B., Zhou, D. H., Zou, Y., Chen, K., Liu, Q., Wang, J. L., et al. (2017a). Vaccination with a DNA vaccine encoding Toxoplasma gondii ROP54 induces protective immunity against toxoplasmosis in mice. Acta Trop. 176, 427-432. doi: 10.1016/j.actatropica.2017.09.007

Yarovinsky, F., Zhang, D., Andersen, J. F., Bannenberg, G. L., Serhan, C. N., Hayden, M. S., et al. (2005). TLR11 activation of dendritic cells by a protozoan profilin-like protein. Science 308, 1626-1629. doi: 10.1126/science.1109893

Zhao, Z., Fux, B., Goodwin, M., Dunay, I. R., Strong, D., Miller, B. C., et al. (2008). Autophagosome-independent essential function for the autophagy protein Atg5 in cellular immunity to intracellular pathogens. Cell Host Microbe 4, 458-469. doi: 10.1016/j.chom.2008.10.003

Zhou, P., Nie, H., Zhang, L. X., Wang, H. Y., Yin, C. C., Su, C., et al. (2010). Genetic characterization of Toxoplasma gondii isolates from pigs in China. J. Parasitol. 96, 1027-1029. doi: 10.1645/GE-2465.1

Zhou, P., Sun, X. T., Yin, C. C., Yang, J. F., Yuan, Z. G., Yan, H. K., et al. (2011). Genetic characterization of Toxoplasma gondii isolates from pigs in southwestern China. J. Parasitol. 97, 1193-1195. doi: 10.1645/ge-2851.1

Conflict of Interest Statement: The authors declare that the research was conducted in the absence of any commercial or financial relationships that could be construed as a potential conflict of interest.

Copyright (c) $2019 \mathrm{Zhu}, \mathrm{Li}$, Pappoe, Shen and Yu. This is an open-access article distributed under the terms of the Creative Commons Attribution License (CC BY). The use, distribution or reproduction in other forums is permitted, provided the original author(s) and the copyright owner(s) are credited and that the original publication in this journal is cited, in accordance with accepted academic practice. No use, distribution or reproduction is permitted which does not comply with these terms. 


\section{GLOSSARY}

\begin{tabular}{|c|c|}
\hline Atgs & $\begin{array}{l}\text { Autophagy-related proteins. Eukaryotic factors participating in various stages of the autophagic process and } \\
\text { required for autophagosome formation. }\end{array}$ \\
\hline CDPKs & $\begin{array}{l}\mathrm{Ca}^{2+} \text {-dependent protein kinases. A family of enzymes that control multiple process of parasite in motility, } \\
\text { adhension, and egress. }\end{array}$ \\
\hline GBPs & IFN- $\gamma$-inducible guanylate-binding proteins. \\
\hline GRAs & $\begin{array}{l}\text { Dense granule protein. Proteins secreted from the parasite dense-granule organelles and take part in most steps } \\
\text { during parasite invasion and evasion. }\end{array}$ \\
\hline$I D O$ & $\begin{array}{l}\text { Indoleamine oxidase. Induced by IFN- } \gamma \text { and degrades tryptophan, an essential nutritional amino acid for the } \\
\text { intracellular growth of } T \text {. gondii in human cells. }\end{array}$ \\
\hline iNOS & $\begin{array}{l}\text { Inducible nitric oxide synthase. An IFN- } \gamma \text {-inducible protein that mediates parasite clearance and growth inhibition } \\
\text { through nitric oxide production. }\end{array}$ \\
\hline IRGs & A family of rodent IFN- $\gamma$-induced GTPases. \\
\hline$L C 3$ & $\begin{array}{l}\text { Microtubule-associated protein } 1 \text { lightchain3. A mammalian autophagosomal ortholog of yeast Atg8 and } \\
\text { contributes to major steps of autophagy. There are two isoforms of LC3, LC3-I (soluble) and LC3-II (membrane- } \\
\text { bound). }\end{array}$ \\
\hline MICs & $\begin{array}{l}\text { Microneme proteins. Proteins secreted from the apically located parasite microneme organelles and contribute to } \\
\text { T.gondii invasion and virulence. }\end{array}$ \\
\hline MJ & $\begin{array}{l}\text { Moving junction. A tight apposition between the host cell and parasite plasma membranes. Anchors the invading } \\
\text { parasite to the host cell and facilitates parasite internalization within a parasitophorous vacuole. }\end{array}$ \\
\hline MMPs & $\begin{array}{l}\text { Matrix metalloproteases. A family of enzymes containing } \mathrm{Ca}^{2+} \text { and } \mathrm{Zn}^{2+} \text { in structure that participate in metabolism } \\
\text { in extracellular matrix. }\end{array}$ \\
\hline NLRP1 & $\begin{array}{l}\text { An inflammasome sensor and a member of the NLR (Nod-like receptor/nucleotide binding domain/leucine rich } \\
\text { repeat containing) protein family. }\end{array}$ \\
\hline$P V($ and $P V M)$ & $\begin{array}{l}\text { Parasitophorous vacuole. An intracellular compartment that the parasite resides in and is bounded by membrane } \\
\text { called PVM. }\end{array}$ \\
\hline RONs & $\begin{array}{l}\text { Rhoptry neck proteins. Proteins secreted from the neck of the rhoptry organelles. A component of the moving } \\
\text { junction that plays a central role during invasion. }\end{array}$ \\
\hline ROPs & $\begin{array}{l}\text { Rhoptry body proteins. Proteins secreted from the bulb or body of the apically located rhoptry organelles of the } \\
\text { parasite and take part in most steps during parasite invasion and evasion. }\end{array}$ \\
\hline STAT & $\begin{array}{l}\text { Signal transducer and activator of transcription. A group of transcription factors that transmit signals from the } \\
\text { extracellular milieu of cells to the nucleus. }\end{array}$ \\
\hline
\end{tabular}

